\title{
Bio-inert Properties of TEG Modified Dendrimer Interface
}

\author{
Yoshiko MiUra, ${ }^{\dagger}$ Yuki KoJima, Hirokazu Seto, and Yu Hoshino \\ Department of Chemical Engineering, Kyushu University, 744 Motoka, Nishi, Fukuoka 819-0395, Japan
}

\begin{abstract}
The bioinert interfaces that prevent adhesion of proteins and cells are important for biomaterial applications. In order to design a bioinert interface, the immobilization of an appropriate functional group and the control of molecular density is required. Dendrimer was modified with triethylene glycol (TEG) to display a dense brush structure. TEG with different density and terminal groups were immobilized with a dendrimer template and thiol terminated molecules. The inhibitory effect on protein and bacteria binding was investigated. The physical property of the interface was measured by QCMadmittance to clarify the factor of the bioinert property.
\end{abstract}

Keywords Bioinert interface, dendrimer, triethylene glycol, QCM-A

(Received October 25, 2020; Accepted December 4, 2020; Advance Publication Released Online by J-STAGE December 11, 2020)

\section{Introduction}

The advancements in biotechnology are fueling demand for advanced biomaterials, for which control of material interfaces is important. Biomaterial interfaces are involved in many aspects of performance, including molecular recognition, cell adhesion, and inflammation. In particular, controlling the adhesion of bio-substances such as proteins and cells is important, and the design of bioinert materials has been intensively investigated for the development of biomaterials with biocompatibility for use in bio-devices and artificial organs..$^{1-3}$ As a result of many studies, polymers such as polyethylene glycol (PEG) ${ }^{4,5}$ and zwitter ionic polymers ${ }^{6,7}$ have been developed. Immobilization of dextran at the interface has been reported. ${ }^{8}$ However, the current technology is still insufficient to control the interface properties as required.

It has been also reported that the structure of water at the material interface is important, and protein adsorption is changed by the molecular mobility of water. ${ }^{9}$ That is, it is significant to refine the design of interfaces with molecular level. The self-assembled monolayer ${ }^{10,11}$ and the polymer brush ${ }^{12}$ are considered to be excellent techniques for controlling the molecular structure of the interface. ${ }^{1}$ However, there are of course limitations to control the interface molecular structure. It is an interesting challenge to control the interface structure with the special molecules like dendrimer.

Dendrimers are uniform and branched polymers. ${ }^{12}$ The dendrimers have special structures that diverge from the center core to the molecular end. It has been reported that dendrimers with high generation have a dense molecular structure. We have reported the control of the interface of dendrimer immobilized material. ${ }^{13}$ The unique performance can be demonstrated by controlling the density and nano-structure with dendrimers. ${ }^{14}$ We have previously reported that a molecular interface with a sugar chain immobilized at the end is realized, and the adhesion

† To whom correspondence should be addressed.

E-mail: miuray@chem-eng.kyushu-u.ac.jp of proteins is greatly different. ${ }^{15}$ In other words, even if the functional groups are the same, their functions differ greatly depending on the density and structure of the molecules immobilized on the interface. ${ }^{16}$ Previous studies have shown that the molecular density of sulfated sugar has a significant effect on protein amyloidosis.

In this study, we have investigated the effect of dense functional groups on the pseudo-brush with dendrimer template. Dense brush layer of triethyleneglycol (TEG) was prepared by TEG dendrimer conjugates. The dendrimer had a core of disulfide group that was reduced to thiols to form a selfassembled monolayer on the gold substrate. Proteins and bacteria were applied to densely packed TEG structures to study their adhesion. Both methoxy and hydroxyl TEG were prepared.

\section{Experimental}

\section{Reagent}

The following reagents were used without purification: chloroform, $\quad \mathrm{N}, \mathrm{N}$-diisopropylethylamine (DIEA) pyridine, sodium borohydride $\left(\mathrm{NaBH}_{4}\right)$, sodium azide $\left(\mathrm{NaN}_{3}\right)$ toluene, (Kanto Pure Chemical, Tokyo Japan), $N, N$-Dimethylformamide (DMF), methanol, potassium thioacetate, succinic anhydride, 2,4,6-trinitrobenzenesulfonic acid sodium salt dihydrate (TNBS), (Fujifilm Wako, Tokyo, Japan), 1-[bis(dimethylamino) methylene]-1H-1,2,3-triazolo[4,5-b]pyridinium 3-oxide hexafluorophosphate (HATU), diethylene glycol 2-bromoethyl methyl ether, 2-[2-(2-chloroethoxy)ethoxyl]ethanol, octadecane thiol (ODT) (TCI, Tokyo Japan), albumin from bovine serum (BSA), fibrinogen, polyamideamine dendrimer with cysteamine core generation 4 (PAMAM, $10 \mathrm{wt} \% \%$ in methanol), polystyrene (PSt) (Sigma-Aldrich Co., St. Louis, MO), concanavalin A (ConA, J-Oil Mills, Tokyo, Japan), and green-fluorescence SYTO9 (SYTO9, Molecular Probes Inc., Eugene, OR).

Staphylococcus epidermidis (S. coccus, Strain JCM 2414) was provided by RIKEN, BRC. E.coli ORN 178 was provided from Prof. T. Ooya (Kobe University). 
<smiles>COCCOCCOCCNC(=O)CCC(=O)Nc1ccccc1</smiles><smiles>O=C(CCC(=O)Nc1ccccc1)NCCOCCOCCO</smiles>

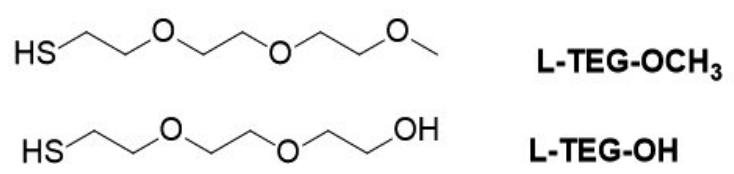

Fig. 1 Chemical structure of TEG derivatives used in this study. G4 indicates PAMAM dendrimer generation 4 with cisteamine core.

\section{Characterization}

Proton nuclear resonance $\left({ }^{1} \mathrm{H}-\mathrm{NMR}\right)$ spectra were recorded on a JEOL-ECP400 spectrometer (JEOL, Tokyo, Japan) using $\mathrm{CDCl}_{3}, \mathrm{MeOD}$, DMSO- $d_{6}$, or $\mathrm{D}_{2} \mathrm{O}$ as a solvent. X-ray photoelectron spectroscopy (XPS) spectra were measured on AXIS-ultra (Shimadzu/Kratos, Kyoto, Japan), and peaks were analyzed with peakfit v4.12 (Systat Software, Inc., CA, USA). FTIR spectra were measured with FTIR spectrum 100 (PerkinElmer Inc., Waltham, MA) equipped with an RAS attachment (Reflector 2, Harrick Scientific Products Inc., Pleasantville, NY). Water contact angle was measured with a DropMaster300 (Kyowa Interface Science Co., Ltd., Saitama, Japan) instrument, and the thicknesses of the SAMs were estimated using an ellipsometer (PZ2000, Royal Philips Electronics, Eindhoven, Netherlands). AFM was measured with D-AFM (D-3000, Bruker AXS K.K., Karlsruhe, Germany) using NCHV-10V probe ((Bruker AXS K.K., Karlsruhe, Germany) and $\mathrm{Au}(111)$ mica ( $\phi 10 \mathrm{~mm}$, PHASIS, Geneva, Switzerland)

\section{Preparation of TEG derivatives}

TEG derivatives with hydroxyl group and methoxy group, and TEG modified dendrimer with cysteamine core were prepared (Fig. 1). The detail of the synthetic procedure is summarized in the Supporting Information.

\section{Substrate preparation}

Gold substrate (Kenis, Osaka, Japan) was cut into $1 \times 1 \mathrm{~cm}$. The substrate was sonicated in MilliQ water and methanol for each $10 \mathrm{~min}$. The substrate was cleaned with $\mathrm{UV} / \mathrm{O}_{3}$ (UV253E, Filgen, Inc., Aichi, Japan) for $30 \mathrm{~min}$. The substrate was cleaned with MilliQ water and methanol and dried under $\mathrm{N}_{2}$.

D-TEG-OCH ${ }_{3}$ and D-TEG-OH were dissolved in water to a concentration of $0.2 \mathrm{mM}$. $\mathrm{NaBH}_{4}(2 \mathrm{~mL})$ and $4 \mathrm{~mL}$ methanol were added to the dendrimer solution to obtain thiol-terminated dendrimer solution. Dendrimer solution was diluted with water toa concentration of $0.1 \mathrm{mM}$. The substrate was immersed in $0.1 \mathrm{mM}$ dendrimer solution for $12 \mathrm{~h}$ and washed with MilliQ water and methanol. The substrate was dried under $\mathrm{N}_{2}$. L-TEG$\mathbf{O C H}_{3}$ and L-TEG-OH was dissolved in MilliQ water to obtain the $0.1 \mathrm{mM}$ solution. The substrate was immersed in $0.1 \mathrm{mM}$ dendrimer solution for $12 \mathrm{~h}$ and washed with MilliQ water and methanol. The substrate was dried under $\mathrm{N}_{2}$.

ODT was dissolved in ethanol to a concentration of $0.1 \mathrm{mM}$. The substrate was immersed in the ODT solution for $12 \mathrm{~h}$. The substrate was washed with MilliQ water and methanol and dried under $\mathrm{N}_{2}$. Pst was coated by spin coating with Opticoat MSA100 (MIKASA Co., Ltd., Tokyo, Japan) using PSt toluene solution $(60 \mu \mathrm{L}, 25 \mathrm{~g} / \mathrm{L})$ at $3000 \mathrm{rpm}$ for $30 \mathrm{~s}$.

\section{Protein adsorption}

The protein adsorption on the surface was evaluated by QCM (AFFINIX Q4, Initium Inc., Kanagawa, Japan). Fibrinogen, and BSA and ConA was used in this experiment. The modified sensor cell was suffused with PBS buffer $(10 \mathrm{mM}, \mathrm{pH} 7.4$, $134 \mathrm{mM} \mathrm{NaCl}, 2.68 \mathrm{mM} \mathrm{KCl}, 1.76 \mathrm{mM} \mathrm{KH} \mathrm{KH}_{2} \mathrm{PO}_{4}, 8.1 \mathrm{mM}$ $\mathrm{Na}_{2} \mathrm{HPO}_{4}$ ) until the frequency reached a steady state. Each protein, at various concentrations, was injected into the sensor cell, and the frequency changes $(\Delta F)$ were recorded.

\section{Bacteria adsorption on the substrate}

E. coli (ORN178) and S. coccus were cultured in LB broth (Lennox) medium (Sigma-Aldrich), and nutrient medium (polypeptone $5 \mathrm{~g} / \mathrm{L}$, beef extract $3 \mathrm{~g} / \mathrm{L}$, and $\mathrm{NaCl} 5 \mathrm{~g} / \mathrm{L}$ ). A solution of $E$. coli and $S$. coccus solution was prepared with cell densities of $10^{8}$ and $10^{7} \mathrm{CFU} / \mathrm{mL}$ with $10 \mathrm{nM}$ SYTO 9. The substrate was immersed into the bacteria solution for $2.5 \mathrm{~h}$ and washed with PBS $5 \mathrm{~mL}$ twice. The bacteria were observed with fluorescence microscope, and analyzed with ImageJ.

\section{Admittance measurement of the substrate with $Q \mathrm{CM}^{17}$}

The admittance of the substrate was measured with $27 \mathrm{MHz}$ QCM (AFFINIX Qn pro, Initium Inc., Kanagawa, Japan). The admittance curve was converted into a conductance curve (conductance-frequency plot) based on an admittance analysis to obtain both the frequency change $(\Delta F)$ and energy dissipation change $(\Delta D)$. The frequency change in the air phase $(\Delta F($ air $))$ and that in aqueous solution (PBS buffer) $(\Delta F($ buffer $))$ can be measured to determine the amount of hydrodynamic water on the interface. The energy dissipation change in water $(\Delta D($ buffer $))$ and the frequency change after drying $(\Delta F($ air $))$ are used to evaluate the viscoelastic properties in the aqueous buffer solution.

\section{Results and Discussion}

\section{Preparation of the modified substrate.}

TEG modified dendrimers (D-TEG-OCH 3 and D-TEG-OH) and thiol-terminated TEG (L-TEG-OCH 3 and L-TEG-OH) were prepared (Fig. 1 and Supporting Information), and confirmed by ${ }^{1} \mathrm{H}-\mathrm{NMR}$. The terminal of dendrimer was converted to TEG, the modification ratio was calculated to be $75 \%$, and 48 TEG units were introduced in one dendrimer.

The obtained TEG derivatives were immobilized on the gold substrate. The surface modification with derivatives were analyzed by XPS, and contact angle measurements (Fig. 2 and Fig. S10). TEG and dendrimer immobilized substrates showed the spectra in $\mathrm{C}(1 \mathrm{~s}), \mathrm{O}(1 \mathrm{~s})$, and $\mathrm{N}(1 \mathrm{~s})$. TEG modified dendrimer showed the peaks at $\mathrm{C}-\mathrm{C}, \mathrm{C}-\mathrm{H}(284.9 \mathrm{eV}), \mathrm{C}-\mathrm{N}(285.7 \mathrm{eV})$, $\mathrm{C}-\mathrm{O}(286.5 \mathrm{eV}), \mathrm{C}=\mathrm{O}(287.8 \mathrm{eV})$, TEG, C-C $(285.8 \mathrm{eV}), \mathrm{C}-\mathrm{O}$ $(284.1 \mathrm{eV})$, and $\mathrm{C}-\mathrm{S}(286 \mathrm{eV})$. The reference hydrophobic substrate of ODT self-assembled monolayer showed only the peak of C-C, C-H $(286 \mathrm{eV})$. The amount of molecular bounds was estimated by XPS peaks of $C(1 s)$ and decrease of $\mathrm{Au}(4 \mathrm{f})$ (Fig. S10). The amount of the molecular immobilization of TEG derivatives were compared with ODT that forms densely packed self-assembled monolayers. The amounts of L-TEGOH and L-TEG-OCH $\mathbf{C H}_{3}$ were estimated to be about $25 \%$ of ODT-self-assembled monolayer (SAM) based on the C(1s) peak 

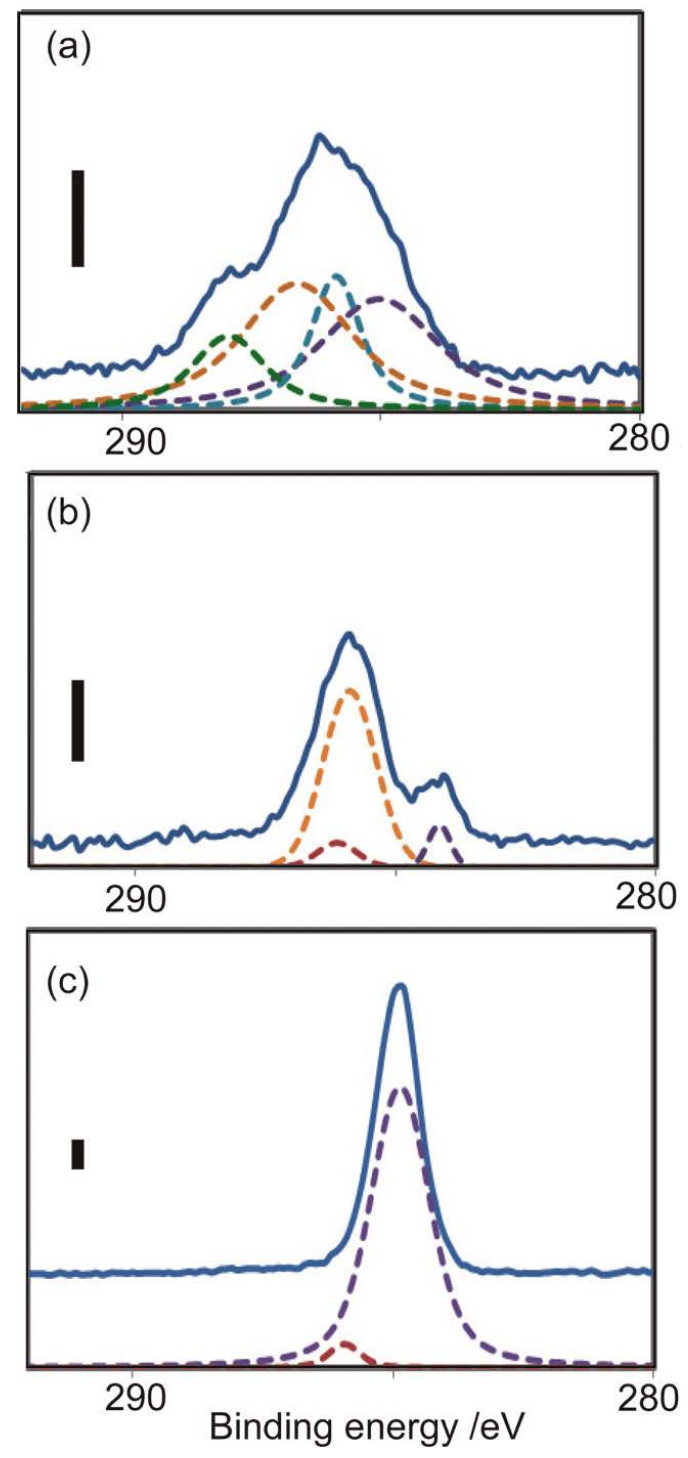

Fig. 2 C1s peak spectra of the modified gold substrates with (a) D-TEG-OCH 3 , (b) L-TEG-OCH 3 and (c) ODT. and the decrease of $\mathrm{Au}(4 \mathrm{f})$ peak. The amount of D-TEG-OH and D-TEG-OCH $\mathbf{C H}_{3}$ was approximately the same as that of ODTSAM.

Contact angles of the substrates of D-TEG-OCH$H_{3}$, D-TEGOH, L-TEG-OCH${ }_{3}$ and L-TEG-OH were $37.3,30.9,58.8$ and 36.0, respectively. The TEG modified substrates showed hydrophilicity, and the TEG-dendrimer substrate showed stronger hydrophilicity than monomeric TEG due to the dense hydrophilic group. The TEG immobilization was also confirmed by AFM and FTIR (Figs. S12 and S13). AFM analysis indicates the immobilization of the spherical dendrimer on the substrate. The thickness of the dendrimer layer is $0.5-1.0 \mathrm{~nm}$, showing the dendrimer monolayer formation on the substrate. In spite of the bulky structure of dendrimer, the thiol-terminated dendrimer formed a self-assembled monolayer on the substrate based on the strong $\mathrm{Au}-\mathrm{S}$ interaction.

\section{Protein adsorption to the TEG modified substrate}

The amount of protein adsorption was varied with the substrates using fibrinogen, and in the order of PSt, L-TEG$\mathrm{OCH}_{3},>$ ODT > L-TEG-OH $>$ D-TEG-OCH 3 > D-TEGOH (Fig. 3). The amount of protein bound on L-TEG-OCH 3 is about 8 times larger than that on D-TEG-OCH${ }_{3}$, and the amount of protein bound on L-TEG-OH is about 7 times larger than that on D-TEG-OH at $\mathrm{C}=0.01 \mathrm{~g} / \mathrm{L}$. The protein bound on D-TEG-OCH ${ }_{3}$ and L-TEG-OCH${ }_{3}$ is larger than that on D-TEG-OH and L-TEG-OH, respectively. The large amount of protein was bound to the hydrophobic surface, but the amount of protein bound was not determined only by the hydrophobicity. PSt and L-TEG-OCH 3 showed larger protein adsorption than the ODT-substrate.

Inhibition of protein adsorption depended on the TEG display. TEG-dendrimer conjugate could display the densely packed TEG brush on the substrate ${ }^{18}$ and it showed a stronger inhibitory effect on protein adsorption than linear TEG. Though the PAMAM dendrimer contains an amine group, the electrostatic interaction by the amine group inside dendrimer was not affected by the protein binding. The dense-TEG structure was effective in terms of the protein inhibitory effect, which was consistent with previous results. ${ }^{1}$ Interestingly L-TEG-OCH${ }_{3}$ modified substrate and PSt showed a similar affinity to protein adsorption. The hydrophobicity of the substrate was favorable to protein (a)

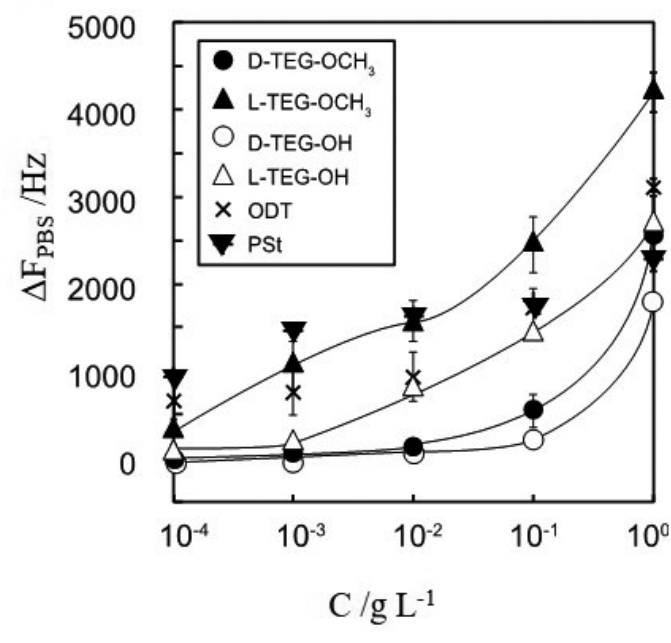

(b)

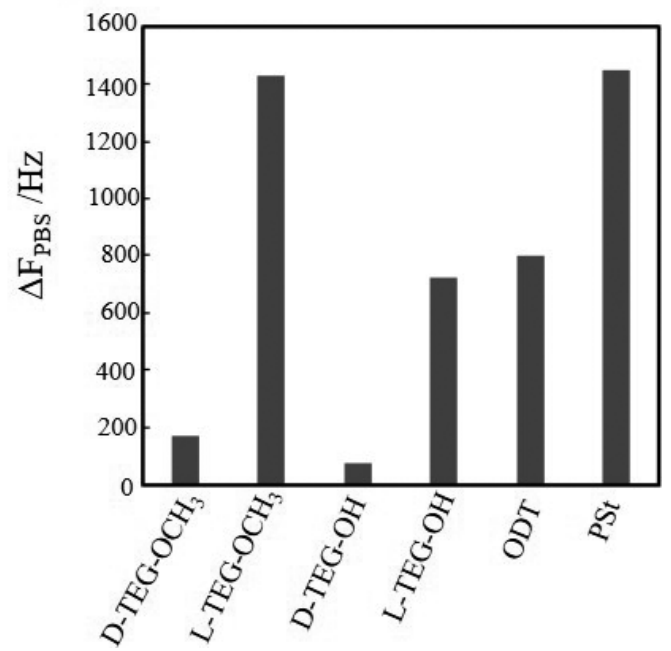

Fig. 3 Amount of fibrinogen adsorption with (a) varying concentration and (b) $C=0.01 \mathrm{~g} / \mathrm{L}$. 


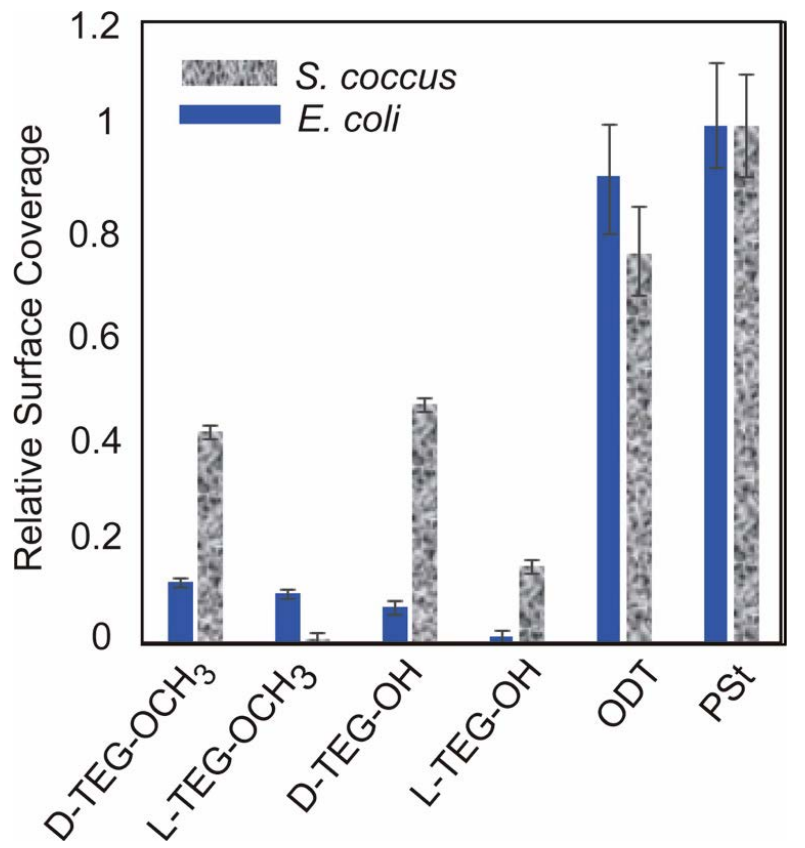

Fig. 4 Relative surface coverage of substrate. The coverage of PSt was defined as 1.0.

adsorption.

In protein adsorption, the TEG-dendrimer showed a better inhibitory effect than the linear. This inhibitory effect of densely packed TEG has been suggested from a report by the Whitesides group, ${ }^{1,18}$ where the SAMs with oligoethylene glycol terminal have a remarkable ability to inhibit protein adsorption. In this study, however, the ability to inhibit protein adsorption was not observed in L-TEG-OH and L-TEG-OCH 3 due to non-dense TEG and hydrophobicity. It is suggested that dendrimertemplated TEG is not a long-chain polymer such as polyethylene glycol, but exhibits an excellent protein inhibitory effect for dense TEG. In view of protein adsorption, dendrimer-TEG substrate was bioinert.

\section{Bacteria adsorption to the substrate}

Bacteria adsorption on the substrate was measured with various substrates (Fig. 4). In the experiment with E. coli, the E. coli adsorption on PSt was suppressed to $12 \%$ or less on the TEG immobilized substrates (D-TEG-OCH 3 , L-TEG-OCH, D-TEG-OH and L-TEG-OH). In particular, the amount of E. coli on L-TEG-OH was $0.002 \%$ of that on PSt, indicating resistance of the substrate to E. coli. When comparing the dendrimer (D-TEG-OCH 3 and D-TEG-OH) and the linear (L-TEG-OCH ${ }_{3}$ and L-TEG-OH) with the same terminal group, the amount of adsorption on the dendrimer-TEG was larger than that on linear TEG at the methoxy terminal and the OH terminal, respectively. In the experiment with $S$. coccus, the $S$. coccus adsorption on TEG immobilized substrate was less than half of that on the PSt substrate. In particular, L-TEG-OCH${ }_{3}$ showed almost no adsorption. When comparing the dendrimer-TEG and linear TEG immobilized substrate with the same terminal groups, the amount of adsorption on the dendrimer TEG was 72.6 times and 3.0 times larger than linear TEG at the methoxy terminal and the $\mathrm{OH}$ terminal, respectively.

The results of PSt and ODT indicated that the interface with large amounts of protein adsorption was also high for bacteria. However, the adsorption behavior TEG interface of dendrimers

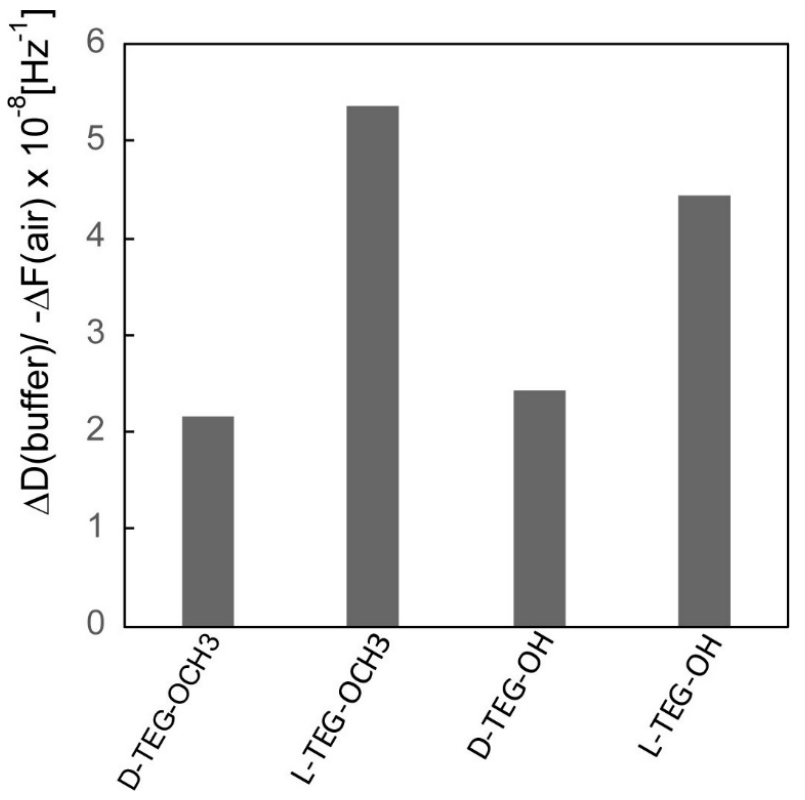

Fig. 5 The results of energy dissipation per unit mass $[\Delta D($ buffer $) /-$ $\Delta F($ air $)]$ by $\mathrm{QCM}-\mathrm{A}$ with various substrates.

and linear showed no correlation between protein and bacteria adsorption. Linear TEG (L-TEG-OCH 3 and L-TEG-OH) showed a strong inhibitory effect on bacteria adsorption, though the linear TEG substrate did not inhibit protein adsorption. In addition, in protein adsorption, the effect of the functional group at the molecular terminal was large, and the methyl ester and hydroxyl group at the terminal had a large effect, but in bacterial adsorption, the effect of the functional group at the terminal was small, and the shape (linear or dendrimer) of the molecules had the most effect. In view of bacteria adsorption, the linear TEG substrate is bioinert.

\section{Viscoelasticity of the substrates}

The viscoelastic properties of the interface with immobilized TEG derivatives were evaluated using QCM-A. QCM is used as a sensitive mass sensor, utilizing the Saureybrey relationship between the resonant frequency and the mass per unit area. ${ }^{19}$ The mass changes can be measured not only in vacuum but also in the aqueous solution as a label-free biosensor. ${ }^{20}$ Since the mass is measured by the difference in resonant frequency of the device, the energy dissipation by viscosity of the device is reflected in the QCM. ${ }^{21}$ The rheological change due to the hydrodynamic water in the aqueous solution is well affected..$^{22}$ It has been reported that the viscoelasticity at the device interface is related to the energy dissipation of the QCM. ${ }^{23}$

The results are shown in Fig. 5. The viscoelasticity of the interface was evaluated by comparing the energy dissipation value $(\triangle D(P B S))$ divided by the polymer fixed amount $(-\Delta F($ air $))$. The result of energy dissipation per unit mass $[\Delta D($ Buffer $)] /(-\Delta F($ air $))]$ was roughly divided into two values around $2.0 \times 10^{-8}\left[\mathrm{~Hz}^{-1}\right]($ D-TEG-OCH 3 and D-TEG-OH) and around $5.0 \times 10^{-8}\left[\mathrm{~Hz}^{-1}\right]$ (L-TEG-OCH 3 and L-TEG-OH). The value of the dendrimer was 2.5 times higher than that of the linear. In the present measurement, since the higher the value of $\Delta D($ Buffer $) /(-\Delta F($ air $))$ shows the more the viscoelastic, it was found that the dendrimer TEG substrate was more elastic than the linear TEG substrate, and that the linear TEG substrate was more viscostic than the dendrimer TEG substrate. The results of 
Okahata et al. suggested that the current dendrimer interface value had similar viscoelasticity to those of proteins. ${ }^{24}$

Figures 4 and 5 suggest that there is a correlation between viscoelasticity and the amount of bacteria bound, even though the molecular thickness is only several nanometers (Fig. S13). It is considered that bacteria are more likely to adsorb to the elastic substrate and less likely to adsorb to the viscous substrate.

It has been reported that not only the inhibition effect of proteins at the interface but also the physical properties of the interface have a great influence on the adsorption of bacteria. It has been reported that viscoelasticity is strongly related to the bacteria adsorption. ${ }^{25}$ Several cells and bacteria were reported to have mechanical property sensitive proteins. ${ }^{26}$ In this study, the terminal functional groups, the contact angle, and the amount of protein bound are not appropriate for the amount of bacterial adhesion, suggesting that the difference in the physicochemical properties of the interface is involved. However, this mechanism needs further investigation.

\section{Conclusion}

Dendrimer terminal was modified with triethylene glycol (TEG) to form dendrimer-TEG conjugates. Densely packed TEG was immobilized on the gold substrate as the dendrimer conjugate. The protein and bacteria adsorption on the TEG modified substrates were investigated. It was found that the dendrimerand the linear- TEG immobilized substrate had an inhibitory effect of the adsorption of proteins and bacteria. However, when the dendrimer- and the linear-TEG were compared, it was found that the dendrimer had a higher inhibitory effect on protein adsorption but a lower inhibitory effect on bacterial adsorption. It was suggested that the physical property of dendrimer TEG interface influenced the adsorption of bacteria.

\section{Acknowledgements}

This study was supported by the Grant-in-Aid for Scientific Research B (JP19H02766), Grant-in-Aid for Challenging Research (Pioneering) (JP19K22971), and Grant-in-Aid for Scientific Research on Innovative Areas (JP20106003, JP20H05230 and JP20H04825), and Eno scientific foundation. We would like to express our appreciation for the fruitful discussion with Prof. Takeshi Hasegawa (Kyoto University).

\section{Supporting Information}

This material is available free of charge on the Web at http:// www.jsac.or.jp/analsci/.

\section{References}

1. K. L. Prime and G. M. Whitesides, Science, 1991, 252,
1164.

2. M. Mrksich, G. M. Sigal, and G. M. Whitesides, Langmuir, 1995, 11, 4383.

3. D. J. Kim, J. M. Lee, and B. G. Chung, Biotechnol. Bioeng., 2011, 108, 1194.

4. D. W. Branch, B. C. Wheeler, G. J. Brewer, and D. E. Leckband, Biomaterials, 2001, 22, 1035.

5. R. Gref, M. Lück, P. Quellec, M. Marchand, E. Dellacherie, S. Harnisch, T. Blunk, and R. H. Müller, Colloids Surf., B, 2000, $18,301$.

6. J. Ladd, Z. Zhang, S. Chen, J. C. Hower, and S. Jiang, Biomacromolecules, 2008, 9, 1357.

7. K. Ishihara, H. Nomura, T. Mihara, K. Kurita, Y. Iwasaki, and N. Nakabayashi, J. Biomed. Mater. Res., 1998, 39, 323.

8. R. A. Frazier, G. Matthijs, M. C. Davies, C. J. Roberts, E. Schacht, and S. J. B. Tendler, Biomaterials, 2000, 21, 957.

9. T. Hatakeyama, M. Tanaka, and H. Hatakeyama, Acta Biomater, 2010, 6, 2077.

10. J. C. Love, L. A. Estroff, J. K. Kriebel, R. G. Nuzzo, and G. M. Whitesides, Chem. Rev., 2005, 105, 1103.

11. M. Krishnamoorthy, S. Hakobyan, M. Ramstedt, and J. Gautrot, Chem. Rev., 2014, 114, 10976.

12. M. J. Fréchet and D. A. Tomalia (ed.), "Dendrimers and Other Dendritic Polymers", 2001, Wiley, New York.

13. E. Matsumoto, T. Fukuda, and Y. Miura, Colloids Surf., B, 2011, 84, 280.

14. S. K. Oh, Y. G. Kim, H. Ye, and R. M. Crooks, Langmuir, 2003, 19, 10420

15. T. Fukuda, E. Matsumoto, S. Onogi, and Y. Miura, Bioconjugate Chem., 2010, 21, 1079.

16. T. Satomi, Y. Nagasaki, H. Kobayashi, H. Otsuka, and K. Kataoka, Langmuir, 2007, 23, 6698.

17. H. Furusawa, T. Sekine, and T. Ozeki, Macromolecules, 2016, 49, 3463.

18. E. Ostuni, R. G. Chapman, M. N. Liang, G. Meluleni, G. Pier, D. E. Ingber, and G. M. Whitesides, Langmuir, 2001, 17, 6336.

19. G. Sauerbrey, Z. Phyzik, 1959, 155, 206.

20. H. Sota, H. Yoshimine, R. F. Whittier, M. Gotoh, Y. Shinohara, Y. Hasegawa, and Y. Okahata, Anal. Chem. 2002, 74, 3592.

21. K. Sadman, C. G. Wiener, R. A. Weiss, C. C. White, K. R. Shull, and B. D. Vogt, Anal. Chem., 2018, 90, 4079.

22. M. V. Voinova, M. Jonson, and B. Kasemo, Biosens. Bioelectron., 2002, 17, 835.

23. J. R. Stokes, L. Macakova, A. Chojnicka-Paszun, C. G. de Kruif, and H. H. de Jongh, Langmuir, 2011, 27, 3474.

24. T. Ozeki, M. Morita, H. Yoshimine, H. Furusawa, and Y. Okahata, Anal. Chem., 2007, 79, 79.

25. P. C. Lau, J. R. Dutcher, T. J. Beveridge, and J. S. Lam, Biophys. J., 2009, 96, 2935.

26. V. Vogel and M. Sheetz, Nat. Rev. Mol. Cell Biol., 2006, 7, 265. 